\title{
Antibiotics and antifungals in silicone oil
}

\author{
Ella H. Leung ${ }^{*}$ (D) and J. Timothy Stout
}

\begin{abstract}
Background: Antimicrobials may be injected into silicone oil-filled eyes with endophthalmitis, but the interaction with oil is unclear. The purpose of the experiment is to determine whether vancomycin, amikacin, and amphotericin B mix with silicone oil.

Methods: Using the relative proportions of the human eye, $4 \mathrm{ml}$ of 1000 centistokes silicone oil was centrifuged with $0.1 \mathrm{ml}$ of vancomycin $1 \mathrm{mg} / 0.1 \mathrm{ml}$, amikacin $0.4 \mathrm{mg} / 0.1 \mathrm{ml}$, or amphotericin B $5 \mu \mathrm{g} / 0.1 \mathrm{ml}$ in vitro and eluted. The aqueous was immediately analyzed with a liquid chromatographer/mass spectrometer and after $24 \mathrm{~h}$.

Results: Within $24 \mathrm{~h}$, a mean of $26.9 \mathrm{\mu mol} / \mathrm{L}$ of vancomycin, $0 \mathrm{nmol} / \mathrm{L}$ of amikacin, and $0 \mathrm{nmol} / \mathrm{L}$ of amphotericin $B$ were recovered. When the concentrations of amikacin and amphotericin $B$ were increased $100-$ fold, $0 \mathrm{nmol} / \mathrm{L}$ of amikacin and $75.7 \mu \mathrm{mol} / \mathrm{L}$ of amphotericin B were recovered.
\end{abstract}

Conclusions: Vancomycin and amphotericin B partially mixed with the silicone oil. Amikacin was not recovered from the antibiotic-silicone oil mixture.

Keywords: Silicone oil, Antibiotics, Antifungals

\section{Background}

Vancomycin, amikacin, and amphotericin B are among the most commonly used intravitreal antibiotics and antifungal agents for the treatment of endophthalmitis. Although intravitreal injections are effective, patients with severe infections or concurrent retinal detachments may benefit from pars plana vitrectomy (PPVs) with silicone oil (SO) tamponades to decrease the bacterial or fungal load, remove inflammatory mediators, and reattach the retina [1]. Previously published studies have reported better visual and anatomic outcomes with PPVs and silicone oil compared to core vitrectomies alone in patients with endophthalmitis.

Silicone oil has been reported to decrease bacterial and fungal survival in vitro. The oil was effective in decreasing the microbial loads of Staphylococcus aureus, Staphylococcus epidermidis, Pseudomonas aeruginosa, Escherichia coli, Fusobacterium spp., Clostridium tertium, Peptotstreptococcus spp., Bacteroides fragilis, Candida albicans, and Aspergillus spp. [2-5]. It is theorized that the viscous oil acts as a physical barrier to deprive the bacteria and fungus of nutrition, and the catalysts and components of

*Correspondence: ehleung@bcm.edu

Cullen Eye Institute, Baylor College of Medicine, 1977 Butler Blvd, Houston, TX 77030, USA the oil may be toxic to the microbes; however, the growth of certain anaerobic bacteria like Propionibacterium acnes and yeast like Candida albicans may not be fully inhibited by the oil $[2,3]$.

The safe and efficacious dose of intravitreal antimicrobials in eyes filled with silicone oil depends on multiple factors, including the dose administered and the amount that may be secluded within the oil or compartmentalized against the retina [6-8]. Retinal toxicity has been reported with ceftazidime $2.25 \mathrm{mg} / 0.2 \mathrm{ml}$ and vancomycin $1.25 \mathrm{mg} / 0.2 \mathrm{ml}$ injected into the $1.5 \mathrm{ml}$ vitreous cavities of rabbit eyes; however, the one-quarter dose was considered safe [7]. Since rabbit eyes are smaller than human eyes, however, a quarter-dose in rabbits is approximately equal to half the usual dose in humans. Many surgeons therefore inject one-half to one-forth of the standard dose of antimicrobials in eyes filled with silicone oil. It is currently unknown whether intravitreal antibiotics and antifungals may mix with the silicone oil itself, thereby becoming a medication reservoir and becoming pharmacologically unavailable.

The purpose of the study is to determine whether vancomycin, amikacin, and amphotericin B mix with silicone oil in vitro.

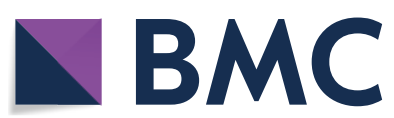

(c) The Author(s) 2019. This article is distributed under the terms of the Creative Commons Attribution 4.0 International License (http://creativecommons.org/licenses/by/4.0/), which permits unrestricted use, distribution, and reproduction in any medium, provided you give appropriate credit to the original author(s) and the source, provide a link to the Creative Commons license, and indicate if changes were made. The Creative Commons Public Domain Dedication waiver (http://creativecommons.org/ publicdomain/zero/1.0/) applies to the data made available in this article, unless otherwise stated. 


\section{Methods}

The methodology is outlined in Fig. 1. The study did not involve human subjects so an Institutional Review Board approval was not required. Standard concentration curves were created using pure samples of vancomycin (Mylan Pharmaceuticals, IL), amikacin (Geneva Pharmaceuticals, NJ), and amphotericin B (X-Gen Pharmaceuticals, NY) in a liquid chromatographer-mass spectrometer (Agilent 6490 Triple-Quadropole LC-MS, CA); the correlation coefficients were $0.97-0.99$ for all 4 antimicrobials. The LC-MS detected nanomolar concentrations. Pure samples of $0.9 \%$ sodium chloride solution $(\mathrm{NaCl}), 5 \%$ dextrose in water (D5W), and distilled water served as controls.

The intravitreal formulations of each medication were compounded. Vancomycin was dissolved in $0.9 \% \mathrm{NaCl}$ to achieve a concentration of $1 \mathrm{mg} / 0.1 \mathrm{ml}$, amikacin in $0.9 \% \mathrm{NaCl}(0.4 \mathrm{mg} / 0.1 \mathrm{ml})$, and amphotericin B in D5W $(5 \mu \mathrm{g} / 0.1 \mathrm{ml})$.
Using the relative proportions of the vitreous cavity, $4 \mathrm{ml}$ of 1000 centistokes silicone oil (Alcon, Fort Worth, TX) was mixed with $0.1 \mathrm{ml}$ of each of the 3 antimicrobials. The experiment was performed in triplicate, and the results were averaged. The "Original SO-Antimicrobial Mix" was vortexed for $2 \mathrm{~min}$ at 15,000 rotations per minute $(\mathrm{rpm})$, and $1.6 \mathrm{ml}$ of only the silicone oil layer was removed, with care taken to not disturb the injected aqueous bubble. Since silicone oil cannot be directly analyzed with the LC-MS, the antibiotics were eluted out of the oil mixture by centrifuging with $1.6 \mathrm{ml}$ of distilled water for $2 \mathrm{~min}$ at 15,000 rpms. Distilled water was used as a solvent because balanced salt solution can cause artifacts and other organic solvents can bind with the silicone oil molecules. The aqueous layer from this "SOAntimicrobial Sample" was immediately analyzed with the LC-MS.

After $24 \mathrm{~h}$, the remainder of the "SO-Antimicrobial Sample" was vortexed for $2 \mathrm{~min}$, and the aqueous

\section{Create standard curves with undiluted antibiotics and antifungals \\ Prepare intravitreal antimicrobials \\ Vancomycin $1 \mathrm{mg} / 0.1 \mathrm{ml}$ \\ Amikacin $0.4 \mathrm{mg} / 0.1 \mathrm{ml}$ \\ Amphotericin B $0.005 \mathrm{mg} / 0.1 \mathrm{ml}$}

Add $0.1 \mathrm{ml}$ of antimicrobials to $4 \mathrm{ml}$ silicone oil to create "Original SO-Antimicrobial Mix"

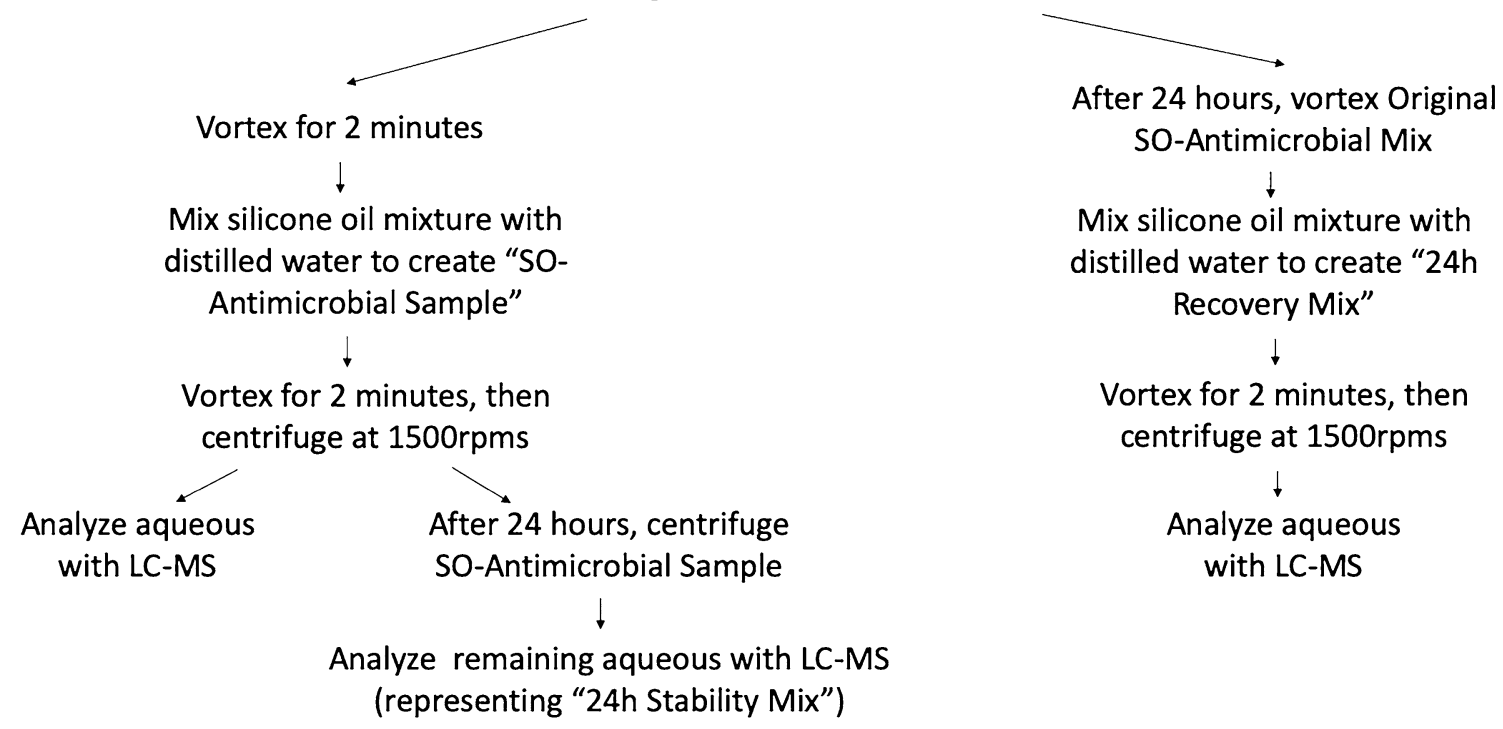

Fig. 1 Procedure protocol. Graphical representation of the protocol. The "SO-Antimicrobial Sample" represents the amount of antimicrobial recovered immediately after injecting the antimicrobials into the silicone oil. The " $24 \mathrm{~h}$ Stability Mix" represents the additional antimicrobials recovered from the "SO-Antimicrobial Sample" after $24 \mathrm{~h}$. The "24 h Recovery Mix" represents the quantity of antimicrobials that had remained in the original silicone oil-antimicrobial mixture and had not diffused out after the first sample 
analyzed with the LC-MS; the new sample represented the stability of antimicrobials being recovered and was referred to as the " 24 h Stability Mix." The "Original SOAntimicrobial Mixture" was also vortexed again after $24 \mathrm{~h} ; 1.6 \mathrm{ml}$ of the silicone oil mixture was removed and centrifuged with $1.6 \mathrm{ml}$ of distilled water to elute out remaining antimicrobials; that mixture represented additional recovery of antimicrobials and was referred to as the "24 h Recovery Mix."

\section{Results}

Immediately after mixing the antimicrobials with silicone oil, a mean of $11.8 \pm 0.11 \mu \mathrm{mol} / \mathrm{l}(\mu \mathrm{M})$ of vancomycin, $0 \mathrm{nmol} / \mathrm{l}(\mathrm{nM})$ of amikacin, and $0 \mathrm{nM}$ amphotericin $\mathrm{B}$ were recovered (Fig. 2). After $24 \mathrm{~h}$, an additional $7.66 \pm 0.06 \mu \mathrm{M}$ vancomycin, $0 \mathrm{nM}$ amikacin, and $0 \mathrm{nM}$ amphotericin $B$ were recovered from the eluted sample, representing the "24 h Stability Mix." An additional $7.43 \pm 0.058 \mu \mathrm{M}$ vancomycin, $0 \mathrm{nM}$ amikacin, and $0 \mathrm{nM}$ amphotericin B were recovered after $24 \mathrm{~h}$ ("24 h Recovery Mix").

Due to the low concentrations of amikacin and amphotericin $\mathrm{B}$ being tested and the heterogeneous properties of the silicone oil-antimicrobial mixture, the experiment was repeated again using 100 times the concentration of amikacin $(40 \mathrm{mg} / 0.1 \mathrm{ml}$, instead of $0.4 \mathrm{mg} / 0.1 \mathrm{ml})$ and amphotericin B $(0.5 \mathrm{mg} / 0.1 \mathrm{ml}$, instead of $0.005 \mathrm{mg} / 0.1 \mathrm{ml})$. While no amikacin was recovered, a mean of $8.62 \pm 0.89 \mu \mathrm{M}$ of amphotericin B was recovered initially from the higher concentration, an additional $40.0 \pm 19 \mu \mathrm{M}$ was obtained from the $24 \mathrm{~h}$ stability sample, and $27.7 \pm 12 \mathrm{mM}$ from the $24 \mathrm{~h}$ recovery sample. Samples where the aqueous bubble had broken up into smaller bubbles had a greater recovery of antimicrobials.

\section{Discussion}

Endophthalmitis is a potentially blinding condition that can occur after intraocular surgery, trauma, or systemic infection. In the Endophthalmitis Vitrectomy Study, only $14 \%$ of patients recovered visual acuity better than $5 / 200$ [8]. Therapies to treat endophthalmitis include intravitreal antibiotics, intravitreal antifungals, and pars plana vitrectomies. In a patient with endophthalmitis and concurrent retinal detachment, silicone oil's potential antimicrobial properties makes it appealing as an intraocular tamponade. Retinal detachments may occur in $4.6-16 \%$ of eyes with endophthalmitis after vitrectomies, compared to less than $5 \%$ in eyes undergoing vitrectomies for other indications [9]; however, the risk of a retinal detachment may be decreased in eyes with concurrent silicone oil implantation $[1,10]$.

The in vitro experiments demonstrated that amphotericin $\mathrm{B}$ and vancomycin partially mixed with the silicone oil while amikacin did not. The chemical properties may help explain the relative antimicrobial recoveries from silicone oil. Silicone oil is composed of a mixture of organic and inorganic, hydrophobic and inert polymers and siloxanes [4]. Vancomycin is primarily hydrophilic but has hydrophobic elements and rings. Amikacin is primarily hydrophilic. Amphotericin B has a hydrophobic polyene chain and a hydrophilic tail and polar head and may be mixed with other compounds like sodium phosphate to increase water solubility (Fig. 2). The more hydrophobic antimicrobials, like amphotericin B interacted to a greater extent with the oil than the hydrophilic antibiotics, like amikacin.

Due to the in vitro nature of the experiments, it was not possible to apply the results to in vivo clinical scenarios; however, the current experiment did provide information regarding the potential of these antimicrobials to mix with silicone oil. While most of the antimicrobials would have been pharmacologically available, a small amount may mix with silicone oil. Given that intravitreal concentrations of antibiotics and antifungals are typically several orders of magnitude higher than the $90 \%$ minimum inhibitory concentrations (MIC90) for most bacterial and fungal organisms $(0.016-32 \mu \mathrm{g} / \mathrm{ml})$, the amount of antimicrobials that would have mixed with the silicone oil would have likely been clinically insignificant [12-14]. The clinician may therefore consider injecting a lower dosage of amikacin since the majority of the injected watersoluble amikacin would be concentrated in the remaining aqueous volume, and amphotericin B may need to be reinjected if the endophthalmitis does not resolve since voriconazole is not fungicidal and may mix with the oil.

The limitations of the current study include the indirect methodology used to quantify the antimicrobials that had partitioned into silicone oil and the low concentrations of antimicrobials used. Some antimicrobials may have been lost in the transfers, diffused out later, were below the limits of detection of the LC-MS, may have diffused out later, or were not mixed homogenously. Silicone oil cannot be directly measured with a LC-MS, so the antimicrobials were eluted out and the concentrations measured on repeat testing. Future studies could include determining the rate at which the antimicrobials are released from silicone oil in vivo, testing the effects of ceftazidime and voriconazole in oil, and using a different type of silicone oil. Unfortunately, ceftazidime was not available during the study due to a manufacturer shortage. The 1000 centistokes silicone oil was used in the current experiments because it is more commonly available, but the more viscous 5000 centistokes silicone oil or heavy silicone oil may be more effective for the complex retinal detachments that may occur with endophthalmitis and in inhibiting bacterial growth [3]. 

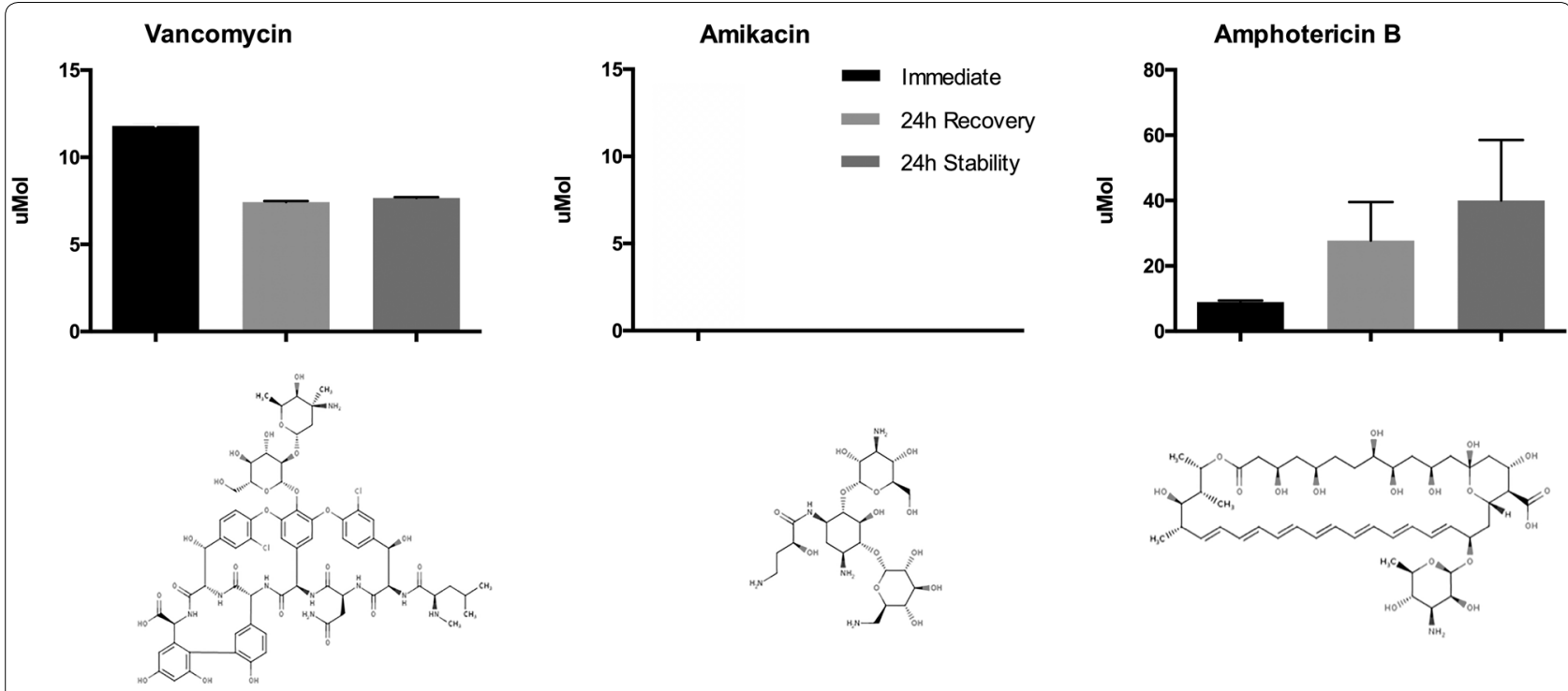

Fig. 2 Antibiotic and antifungals recovered from silicone oil. The graph demonstrates that small quantities of vancomycin and amphotericin $B$ mixed with silicone oil. Although none of the amphotericin B was recovered when the intravitreal concentrations were used ( $5 \mathrm{mcg} / 0.1 \mathrm{ml})$, amphotericin B was recovered when $500 \mathrm{mcg} / 0.1 \mathrm{ml}$ was used

In conclusion, the in vitro experiments demonstrated that a small proportion of vancomycin and amphotericin mixed with silicone oil. Amikacin was not recovered from silicone oil, even after increasing its concentration. It is likely that the remaining unbound antimicrobials would be pharmacologically available.

\section{Acknowledgements}

Not applicable.

\section{Authors' contributions}

EHL and JTS designed and implemented the study and wrote the manuscript. Both authors read and approved the final manuscript.

\section{Funding}

The research was supported by an unrestricted grant from the Research to Prevent Blindness. The funding source had no role in the design, execution, analysis, interpretation, or decision to submit the results of the study.

\section{Availability of data and materials}

The data generated or analyzed in this study are included in this published article and are available from the corresponding author on reasonable request.

\section{Ethics approval and consent to participate}

Not applicable.

\section{Consent for publication}

Not applicable.

\section{Competing interests}

The authors declare that they have no competing interests.

Received: 1 July 2019 Accepted: 4 November 2019

Published online: 12 December 2019

\section{References}

1. Nagpal M, Jain P, Nagpal K. Pars plana vitrectomy with or without silicone oil endotamponade in surgical management of endophthalmitis. Asia Pac J Ophthalmol (Phila). 2012;1 (4):216-21.

2. Yan $\mathrm{H}, \mathrm{Li}$ J. An experimental study on antimicrobial activity of silicone oil in vitro. Ophthalmologica. 2008;222(4):245-8.

3. Ornek N, Apan T, Oğurel R, Ornek K. Comparison of the antimicrobial effect of heavy silicone oil and conventional silicone oil against endophthalmitis-causing agents. Indian J Ophthalmol. 2014;62(4):388-91.

4. Ozdamar A, Aras C, Ozturk R, Akin E, Karacorlu M, Ercikan C. In vitro antimicrobial activity of silicone oil against endophthalmitis-causing agents. Retina. 1999;19(2):122-6.

5. Arici $C$, Aras $C$, Tokman $H B$, Torun MM. An in vitro experimental study on the antimicrobial activity of silicone oil against anaerobic bacteria. Ocul Immunol inflamm. 2016;24(2):173-7.

6. Ornek N, Apan T, Ogurel R, Ornek K. Comparison of the antimicrobial effect of heavy silicone oil and conventional silicone oil against endophthalmitis-causing agents. Indian J Ophthalmol. 2014;62(4):388-91.

7. Hegazy HM, Kivilcim M, Peyman GA, et al. Evaluation of toxicity of intravitreal ceftazidime, vancomycin, and ganciclovir in a silicone oil-filled eye. Retina. 1999;19(6):553-7.

8. Results of the Endophthalmitis Vitrectomy Study. A randomized trial of immediate vitrectomy and of intravenous antibiotics for the treatment of postoperative bacterial endophthalmitis. Endophthalmitis Vitrectomy Study Group. Arch Ophthalmol. 1995;113(12):1479-96.

9. Dave VP, Pathengay A, Relhan N, Sharma P, Jalali S, Pappuru RR, Tyagi M, Narayanan R, Chhablani J, Das T, Flynn HW Jr. Endophthalmitis and concurrent or delayed-onset rhegmatogenous retinal detachment managed with pars plana vitrectomy, intravitreal antibiotics, and silicone oil. Ophthalmic Surg Lasers Imaging Retina. 2017;48(7):546-51.

10. Do T, Hon DN, Aung T, Hien ND, Cowan CL Jr. Bacterial endogenous endophthalmitis in Vietnam: a randomized controlled trial comparing vitrectomy with silicone oil versus vitrectomy alone. Clin Ophthalmol. 2014;28(8):1633-40

11. Radhika M, Mithal K, Bawdekar A, et al. Pharmacokinetics of intravitreal antibiotics in endophthalmitis. J Ophthalmic Inflamm Infect. 2014;4:22.

12. Marangon FB, Miller $D$, Giaconi JA, Alfonso EC. In vitro investigation of voriconazole susceptibility for keratitis and endophthalmitis fungal pathogens. Am J Ophthalmol. 2004;137(5):820-5. 
13. Harper T, Miller D, Flynn HW Jr. In vitro efficacy and pharmacodynamic indices for antibiotics against coagulase-negative staphylococcus endophthalmitis isolates. Ophthalmology. 2007;114(5):871-5.

14. Sridhar J, Kuriyan AE, Flynn HW Jr, Miller D. Endophthalmitis caused by Pseudomonas aeruginosa: clinical features, antibiotic susceptibilities, and treatment outcomes. Retina. 2015;35(6):1101-6.

\section{Publisher's Note}

Springer Nature remains neutral with regard to jurisdictional claims in published maps and institutional affiliations.
Ready to submit your research? Choose BMC and benefit from:

- fast, convenient online submission

- thorough peer review by experienced researchers in your field

- rapid publication on acceptance

- support for research data, including large and complex data types

- gold Open Access which fosters wider collaboration and increased citations

- maximum visibility for your research: over 100M website views per year

At BMC, research is always in progress.

Learn more biomedcentral.com/submissions 